ARTÍCULO

\title{
Representaciones discursivas de las mujeres en la historia escolar chilena (1810-2017)
}

\author{
Humberto Andrés Álvarez Sepúlvedal (D)
}

\section{RESUMEN}

En este artículo se analizan las representaciones de las mujeres presentes en los manuales que abordan la historia de Chile desde 1810 (año de la Primera Junta Nacional de Gobierno) hasta el 2017 (año de publicación del manual más reciente de la muestra analizada). Con este propósito, se desarrolló una investigación cualitativa basada en un análisis hermenéutico de los textos e imágenes de una muestra intencionada compuesta por 13 libros publicados entre 2009 y 2017 por tres editoriales chilenas (Zig-Zag, Santillana y SM). Se concluye que el discurso pedagógico tiende a invisibilizar o atenuar la actuación femenina en la historia republicana chilena a partir de una serie de convenciones, tales como la supresión, la exclusión parcial, la relevancia histórica categorizada, la asignación de roles pasivos, la representación generalizada y la pretensión de mostrar una perspectiva "neutral" de la historia.

PALABRAS CLAVE

historia escolar chilena; mujeres; manual; representación discursiva.

'Universidad Católica de la Santísima Concepción, Concepción, Chile. 


\title{
DISCURSIVE REPRESENTATIONS OF WOMEN IN CHILEAN SCHOOL HISTORY (1810-2017)
}

\begin{abstract}
This article analyzed the representations of the women present in the manuals that approach the history of Chile from 1810 (year of the First National Governing Board) to 2017 (year of publication of the most recent manual of the sample analyzed). For this purpose, a qualitative research was developed based on a hermeneutic analysis of the texts and images of an intentional sample of 13 books published between 2009 and 2017 by three Chilean publishers (Zig-Zag, Santillana, and SM). It is concluded that the pedagogical speech tends to make invisible or to attenuate the feminine participation in the Chilean republican history from a series of conventions, such as the suppression, the partial exclusion, the categorized historical relevance, the assignment of passive roles, the generalized representation, and the pretension to show a "neutral" perspective of history.

KEYWORDS
\end{abstract}

Chilean school history; women; textbook; discursive representation.

\section{REPRESENTAÇÕES DISCURSIVAS DAS MULHERES NA HISTÓRIA ESCOLAR CHILENA (1810-2017)}

\section{RESUMO}

Este artigo analisou as representações das mulheres presentes nos manuais que abordam a história do Chile desde 1810 (ano da Primeira Junta do Governo Nacional) até 2017 (ano de publicação do manual mais recente da amostra analisada). Para esse fim, foi desenvolvida uma pesquisa qualitativa baseada em uma análise hermenêutica dos textos e imagens de uma amostra intencional de 13 livros publicados entre 2009 e 2017 por três editoras chilenas (Zig-Zag, Santillana e SM). Concluiu-se que o discurso pedagógico tende a tornar invisível ou atenuar o desempenho feminino na história republicana chilena com base em uma série de convenções, tais como a supressão, exclusão parcial, relevância histórica categorizada, atribuição de papéis passivos, representação generalizada e a pretensão de mostrar uma perspectiva "neutra" da história.

\section{PALAVRAS-CHAVE}

história escolar chilena; mulheres; manual; representação discursiva. 


\section{INTRODUCCIÓN}

En los últimos cincuenta años, se evidencia que la igualdad entre hombres y mujeres ha evolucionado de forma progresiva en las sociedades occidentales (Pinedo, Arroyo y Berzosa, 2018). Sin embargo, este avance logrado no es suficiente porque, si bien hay leyes que lo respaldan, los valores actuales y la herencia de costumbres androcéntricas ha provocado que la discriminación de género siga prevaleciendo en la cotidianidad de las personas. Esto se suele observar en la desvaloración del trabajo doméstico femenino, en el creciente predominio de la violencia sexual y en las dificultades que tienen las mujeres para acceder a determinados puestos laborales.

Esta disparidad, como precisa García (2019), se basa principalmente en la existencia de modelos sexistas que imperan en la sociedad, los cuales han sido transmitidos generacionalmente por diversas instituciones sociales como la familia y la escuela. Dentro de la familia, la mujer ha sido relegada al ámbito del hogar por el discurso de la domesticidad, y en la escuela, el curriculum vigente, principalmente a través de los manuales escolares, atribuye un tratamiento pasivo a las mujeres dentro de los procesos sociales e históricos (Llorent y Cobano, 2014; Fernández, 2017; Fernández y Baeza, 2018).

Respecto a esto último, un estudio liderado por Clark et al. (2005) y otro encabezado por Southworth, Kempen y Zielinski (2019) demuestran que los textos de historia mundial que se han editado en Estados Unidos desde los sesenta tienden a invisibilizar de forma significativa a las figuras femeninas. Este mismo problema, como señala Minte y González (2015), se ha constatado en los libros de historia nacional que se han producido en Cuba desde los años noventa. Algo similar ocurre en España, pues, por ejemplo, la discriminación de género en los manuales de Filosofía se traduce en la presencia de sesgos sexistas asociados a los tradicionales ámbitos de desempeño de mujeres y hombres, principalmente proyectados a través de imágenes (Llorent y Cobano, 2014). Y así, suman y siguen, los ejemplos en el mundo occidental.

En el caso particular de Chile, aunque actualmente existe una mayor concientización para recuperar la memoria de las mujeres que fueron relevantes en la historia nacional, se continúa relegando su presencia y participación a través de la exclusión, la generalización y la asignación de roles pasivos (Minte y González, 2015; Fernández, 2017; Fernández y Baeza, 2018).

El presente artículo analiza las representaciones de las mujeres presentes en los libros de texto que abordan la historia chilena desde 1810 (año de la Primera Junta Nacional de Gobierno) hasta el 2017 (año de publicación del manual más reciente de la muestra analizada). Para tal objetivo, se llevó a cabo un análisis hermenéutico del discurso escrito e iconográfico de 13 manuales escolares publicados entre 2009 y 2017 por tres editoriales (Zig-Zag, Santillana y SM) que poseen el monopolio de este rubro en Chile.

\section{TEXTO ESCOLAR, DISCURSO ANDROCÉNTRICO Y PRÁCTICAS DOCENTES}

Woyshner y Schocker (2015), Fernández (2017), Islam y Asadullah (2018) y Kostas (2021) señalan que los manuales escolares presentan y organizan los contenidos que se consideran indispensables desde la perspectiva gubernamental para el apren- 
dizaje del alumnado, pues, siguiendo a Gómez, Vivas y Miralles (2019), siempre han tenido como finalidad reunir el conjunto de verdades fundamentales que todo alumno debe conocer, saber y creer; conocimientos, saberes y creencias que tradicionalmente se presentan en estos materiales como cerrados, inmutables, excluyentes y acabados.

Esta carga ideológica se traduce en diferentes sesgos en la historia enseñada, tales como los referentes a los ideales políticos, los valores religiosos, la diversidad cultural y la diferencia de género (Saenz, 2015; Gómez y Gallego, 2016; Chisholm, 2018). Respecto a esta última disimilitud, es importante mencionar que los discursos patriarcales siguen siendo protagonistas en las prácticas docentes relacionadas con el manejo de materiales didácticos. Un referente de esto es el uso abusivo del texto escolar porque, debido a su narrativa androcéntrica, garantiza la posición dominante de los hombres y favorece la legitimación de consensos en torno a creencias que tributan a la marginación del rol femenino en la historia.

En el caso chileno, por ejemplo, la utilización de manuales de Historia, Geografía y Ciencias Sociales distribuidos por el Ministerio de Educación (MINEDUC) se asocia con fuerza a varios de los objetivos de trabajo en clase, con porcentajes iguales o superiores al $80 \%$; asimismo, es relevante notar que en esta asignatura se alcanzan los mayores porcentajes de uso del texto entre los docentes (Olivera, 2016).

Debido al predominio de esta práctica, existe una alta probabilidad de que el manual no sea lo suficientemente cuestionado por el profesorado, con el consecuente riesgo de promover un aprendizaje pasivo y memorístico en los estudiantes, ya que si el docente no reflexiona sobre qué y para qué enseña jamás será posible generar un cambio en la enseñanza tradicional. Es decir, si el docente no es capaz de utilizar su pensamiento histórico para analizar las ausencias de género en el curriculum, especialmente en los libros escolares, será inviable generar en el alumnado dicha habilidad.

De igual modo, es importante atender no solo a las disposiciones curriculares oficiales, ya que también se debe considerar el curriculum oculto, es decir, todas aquellas normas, actitudes, expectativas, creencias y prácticas no oficiales que los estudiantes aprenden en el contexto escolar. La escuela, especialmente el cuerpo docente, no solo tiene que evitar la reproducción de conductas discriminatorias, sino que debe intervenir para promocionar la igualdad entre los géneros y la prevención de la violencia, en todas sus formas, hacia las mujeres (Díez, 2015; Domínguez, López y Nieto, 2019).

Por esto último, como señalan Grana y Lara (2019), resulta fundamental considerar que el manual escolar actúa como mediador entre el profesor y el estudiante, pues además de aportar conocimientos sobre la asignatura, transmite modelos culturales y estereotipos de género que inciden en el comportamiento y en las creencias del alumnado.

\section{METODOLOGÍA}

Es una investigación cualitativa basada en un análisis hermenéutico (Ballén, Pulido y Zúñiga, 2007) del discurso escrito e iconográfico de los manuales seleccionados (Tabla 1). Al respecto, cabe destacar que la muestra es intencionada (Linares, 2019) y que los criterios utilizados para seleccionar los textos escolares fueron los siguientes: 
Tabla 1 - Muestra de manuales escolares.

\begin{tabular}{|c|c|c|c|c|}
\hline Año & Autor(es) & Texto & Editorial & $\begin{array}{c}\text { Grupo propietario/ } \\
\text { Línea editorial }\end{array}$ \\
\hline 2009 & $\begin{array}{c}\text { Verónica Méndez } \\
\text { Carolina Santelices } \\
\text { Rodrigo Martínez } \\
\text { Isidora Puga } \\
\end{array}$ & $\begin{array}{c}\text { Historia, Geografía } \\
\text { y Ciencias Sociales } 2^{\circ} \\
\text { medio }\end{array}$ & Santillana & $\begin{array}{l}\text { Grupo Prisa/ } \\
\text { Tradicional }\end{array}$ \\
\hline 2010 & $\begin{array}{c}\text { Gonzalo Álvarez } \\
\text { Macarena Barahona }\end{array}$ & $\begin{array}{l}\text { Historia, Geografia } \\
\text { y Ciencias Sociales } 4^{\circ} \\
\text { medio }\end{array}$ & Zig-Zag & $\begin{array}{c}\text { Familia Edwards/ } \\
\text { Tradicional }\end{array}$ \\
\hline 2012 & $\begin{array}{c}\text { Gonzalo Álvarez } \\
\text { Macarena Barahona }\end{array}$ & $\begin{array}{c}\text { Historia, Geografía } \\
\text { y Ciencias Sociales } \\
6^{\circ} \text { básico }\end{array}$ & Zig-Zag & $\begin{array}{c}\text { Familia Edwards/ } \\
\text { Tradicional }\end{array}$ \\
\hline 2012 & $\begin{array}{c}\text { Sebastián Quintana } \\
\text { Sandra Castillo } \\
\text { Nataly Pérez } \\
\text { Cristina Moyano } \\
\text { Luis Thielemann }\end{array}$ & $\begin{array}{c}\text { Historia, Geografía } \\
\text { y Ciencias Sociales } 3^{\circ} \\
\text { medio }\end{array}$ & $\begin{array}{l}\text { Ediciones } \\
\text { SM }\end{array}$ & $\begin{array}{l}\text { Grupo SM/ } \\
\text { Tradicional }\end{array}$ \\
\hline 2013 & $\begin{array}{c}\text { Elizabeth Moreno } \\
\text { Abraham Paulsen } \\
\text { Francisco Villarreal } \\
\text { Cecilia Valdés }\end{array}$ & $\begin{array}{c}\text { Historia, Geografía } \\
\text { y Ciencias Sociales } \\
1^{\circ} \text { básico }\end{array}$ & Santillana & $\begin{array}{c}\text { Grupo Prisa/ } \\
\text { Tradicional }\end{array}$ \\
\hline 2013 & $\begin{array}{c}\text { Gonzalo Álvarez } \\
\text { Macarena Barahona }\end{array}$ & $\begin{array}{c}\text { Historia, Geografía } \\
\text { y Ciencias Sociales } \\
6^{\circ} \text { básico } \\
\end{array}$ & Zig-Zag & $\begin{array}{c}\text { Familia Edwards/ } \\
\text { Tradicional }\end{array}$ \\
\hline 2013 & $\begin{array}{l}\text { María Mendizábal } \\
\text { Jorge Riffo }\end{array}$ & $\begin{array}{c}\text { Historia, Geografia } \\
\text { y Ciencias Sociales } 2^{\circ} \\
\text { medio }\end{array}$ & $\begin{array}{l}\text { Ediciones } \\
\text { SM }\end{array}$ & $\begin{array}{l}\text { Grupo SM/ } \\
\text { Tradicional }\end{array}$ \\
\hline 2013 & $\begin{array}{l}\text { Ignacio Latorre } \\
\text { Mireya Henríquez }\end{array}$ & $\begin{array}{c}\text { Historia, Geografía } \\
\text { y Ciencias Sociales } 3^{\circ} \\
\text { medio }\end{array}$ & Zig-Zag & $\begin{array}{c}\text { Familia Edwards/ } \\
\text { Tradicional }\end{array}$ \\
\hline 2013 & $\begin{array}{c}\text { Ignacio Latorre } \\
\text { Michelle Henríquez } \\
\text { Paloma Rocha }\end{array}$ & $\begin{array}{c}\text { Historia, Geografia } \\
\text { y Ciencias Sociales } 4^{\circ} \\
\text { medio }\end{array}$ & Zig-Zag & $\begin{array}{c}\text { Familia Edwards/ } \\
\text { Tradicional }\end{array}$ \\
\hline 2015 & $\begin{array}{l}\text { Cristian Fernández } \\
\text { Georgina Giadrosić }\end{array}$ & $\begin{array}{c}\text { Historia, Geografía } \\
\text { y Ciencias Sociales } \\
5^{\circ} \text { básico } \\
\end{array}$ & $\begin{array}{l}\text { Ediciones } \\
\text { SM }\end{array}$ & $\begin{array}{l}\text { Grupo SM/ } \\
\text { Tradicional }\end{array}$ \\
\hline 2015 & $\begin{array}{l}\text { Cristian Fernández } \\
\text { Georgina Giadrosić }\end{array}$ & $\begin{array}{c}\text { Historia, Geografía } \\
\text { y Ciencias Sociales } \\
6^{\circ} \text { básico } \\
\end{array}$ & $\begin{array}{l}\text { Ediciones } \\
\text { SM }\end{array}$ & $\begin{array}{l}\text { Grupo SM/ } \\
\text { Tradicional }\end{array}$ \\
\hline 2016 & $\begin{array}{c}\text { José Morales } \\
\text { Sergio Pastene } \\
\text { Carolina Santelices } \\
\text { Sebastián Quintana }\end{array}$ & $\begin{array}{c}\text { Historia, Geografia } \\
\text { y Ciencias Sociales } 1^{\circ} \\
\text { medio }\end{array}$ & Santillana & $\begin{array}{c}\text { Grupo Prisa/ } \\
\text { Tradicional }\end{array}$ \\
\hline 2017 & $\begin{array}{c}\text { Sofía Honeyman } \\
\text { Camila Silva } \\
\text { Sebastián Quintana } \\
\text { Carolina Santelices }\end{array}$ & $\begin{array}{c}\text { Historia, Geografia } \\
\text { y Ciencias Sociales } 2^{\circ} \\
\text { medio }\end{array}$ & Santillana & $\begin{array}{c}\text { Grupo Prisa/ } \\
\text { Tradicional }\end{array}$ \\
\hline
\end{tabular}

Fuente: elaboración propia (2019). 
que comprendan diferentes editoriales; que aborden la historia chilena desde 1810 hasta el 2017; que abarquen distintos niveles de enseñanza; que sean distribuidos por el MINEDUC; y que hayan sido publicados desde el 2009 en adelante.

El estudio hermenéutico de este corpus de libros escolares se fundamenta en el análisis del discurso orientado textualmente (Van Leeuwen, 1996; Fairclough, 2003; Londoño y Bermúdez, 2013). En este trabajo, dicho modelo ayuda a poner énfasis en el análisis de los elementos que forman parte del mundo social y que portan significados representacionales de este. En este contexto, siguiendo a Londoño y Bermúdez (2013), la semiótica es usada como la opción teórica más idónea para emprender un análisis discursivo sobre las interacciones humanas, las identidades sociales y los valores culturales.

La investigación también se sustenta en el método histórico discursivo (Scott, 2009; Wodak, 2009; Londoño y Bermúdez, 2013). Este enfoque permite, tal como señala Londoño y Bermúdez (2013), realizar un triple análisis: una crítica inmanente, es decir, el hallazgo de inconsistencias y contradicciones presentes en las estructuras internas de los discursos ya existentes; una crítica socio-diagnóstica, la cual utiliza el conocimiento previo y contextual de la realidad para situar los elementos comunicativos e interaccionales de un evento discursivo en un marco más amplio de relaciones políticas y sociales; y, por último, una crítica prognóstica, que permite contribuir a la transformación y mejora del proceso comunicativo.

De igual modo, se utilizaron los planteamientos propuestos por Jurjo Torres (1998) para analizar las distorsiones contenidas en los manuales a partir de la selección curricular de contenidos que se concibe desde el paradigma historiográfico androcéntrico. En esta línea, cabe destacar que los proyectos curriculares, los contenidos de la enseñanza, los materiales didácticos, los modelos organizativos de los colegios y las conductas del alumnado y del profesorado no se pueden contemplar como cuestiones técnicas y neutrales, sino que, necesariamente, se deben concebir dentro del marco ideológico que proyecta la clase dominante sobre el resto de la sociedad.

Para emprender el análisis discursivo de los textos de la muestra, se tienen en cuenta las tres modalidades discursivas sugeridas por Torres (1998) y que son utilizadas por los grupos intelectuales al servicio de un determinado modelo social para mantener el statu quo. La primera operación discursiva subraya únicamente las parcelas o rasgos existentes de aquella realidad que refuerza los intereses del poder dominante, o bien se dedica a negar lo existente; la segunda modalidad busca disfrazar una realidad difícil de ocultar, a partir de una etiqueta que proporcione alguna razón explicativa que permita una posible justificación o evasión de responsabilidades; por último, la tercera sostiene que, en el caso de aquellas situaciones en que no se puede esconder la realidad, existe la alternativa de defender la imposibilidad de actuar de forma diferente, o bien de intentar convencer a la sociedad de que por el momento no es posible modificar el orden establecido.

A partir de la combinación de los tres enfoques, se seleccionaron, adaptaron y definieron de forma flexible las categorías y subcategorías de análisis necesarias para desarrollar el propósito de la investigación. La Tabla 2 presenta el detalle respectivo: aquellas relacionadas con la presencia de actores sociales, los niveles de abstracción, los roles asignados, la representación y la relevancia histórica se enmarcan en los modelos de análisis del discurso orientado textualmente; y las operaciones discur- 
Tabla 2 - Categorías de análisis utilizadas.

\begin{tabular}{|c|c|c|}
\hline $\begin{array}{l}\text { Categorías } \\
\text { asociadas a la } \\
\text { participación de los } \\
\text { actores sociales en } \\
\text { el discurso }\end{array}$ & $\begin{array}{c}\text { Sub- } \\
\text { categorías }\end{array}$ & Descriptor \\
\hline \multirow{3}{*}{ Presencia de los actores } & Supresión & $\begin{array}{l}\text { No están en ninguna parte del texto, ya que se busca negar } \\
\text { la existencia de aquellos actores sociales que no forman } \\
\text { parte del discurso hegemónico difundido por los grupos } \\
\text { dominantes. }\end{array}$ \\
\hline & $\begin{array}{l}\text { Exclusión } \\
\text { parcial }\end{array}$ & $\begin{array}{l}\text { Están en un segundo plano, pues, aunque los sujetos } \\
\text { aparezcan mencionados en el discurso, no se clarifica su } \\
\text { importancia o participación dentro de los hechos narrados. }\end{array}$ \\
\hline & Prominencia & $\begin{array}{l}\text { Se presentan de forma relevante y reiterativa porque se } \\
\text { suele destacar a ciertos individuos o grupos sociales como } \\
\text { protagonistas dentro del relato. }\end{array}$ \\
\hline \multirow[b]{2}{*}{ Roles asignados } & Activos & $\begin{array}{l}\text { Son representados como una fuerza dinámica o como } \\
\text { ejecutores de una actividad concreta para remarcar } \\
\text { solamente los atributos que contribuyen a resguardar los } \\
\text { intereses de las clases dirigentes. }\end{array}$ \\
\hline & Pasivos & $\begin{array}{l}\text { Aparecen como receptores de una acción o bien como } \\
\text { actores periféricos que no realizan ninguna actividad } \\
\text { específica. De tal modo, tienden a ser presentados como } \\
\text { un elemento adosado a la acción liderada por los sujetos } \\
\text { protagónicos presentes en el discurso. }\end{array}$ \\
\hline \multirow[t]{2}{*}{ Representación } & Específica & $\begin{array}{l}\text { Los actores son expuestos con una identidad individual y } \\
\text { se pueden reconocer fácilmente mediante su nombre u otro } \\
\text { carácter nominal. Esta forma de representación tiene como } \\
\text { objetivo relevar de manera nominada el protagonismo de } \\
\text { los individuos que lideran una acción o proeza dentro de } \\
\text { la narrativa. }\end{array}$ \\
\hline & Generalizada & $\begin{array}{l}\text { Se presentan de forma colectiva y anónima para suprimir } \\
\text { las identidades y los liderazgos de los actores sociales que } \\
\text { desempeñaron un rol activo, autónomo y decisivo en los } \\
\text { procesos descritos. }\end{array}$ \\
\hline \multirow[b]{2}{*}{ Relevancia histórica } & Propia & $\begin{array}{l}\text { Tienen relevancia histórica propia y autónoma porque } \\
\text { los actores son relevantes por su propio mérito, ya que no } \\
\text { requieren de otro individuo o grupo para sobresalir dentro } \\
\text { del discurso. }\end{array}$ \\
\hline & Categorizada & $\begin{array}{l}\text { Solo tienen relevancia cuando se relacionan con algún actor } \\
\text { protagonista, ya que los sujetos expuestos no son destacados } \\
\text { por sus propios méritos, o bien aparecen consignados como } \\
\text { un elemento complementario o dependiente de los grupos } \\
\text { hegemónicos. }\end{array}$ \\
\hline $\begin{array}{l}\text { Nivel de abstracción o } \\
\text { concreción }\end{array}$ & \multicolumn{2}{|c|}{$\begin{array}{l}\text { Se plantea que los eventos del mundo social pueden representarse en } \\
\text { niveles concretos, intermedios o de alta abstracción con el fin de graduar la } \\
\text { visualización de la problemática o la relación del actor social con el resto de } \\
\text { los agentes. }\end{array}$} \\
\hline
\end{tabular}


Tabla 2 - Continuación

\begin{tabular}{l|l|l}
\hline $\begin{array}{c}\text { Categorías } \\
\text { asociadas a la } \\
\text { participación de los } \\
\begin{array}{c}\text { actores sociales en } \\
\text { el discurso }\end{array}\end{array}$ & $\begin{array}{c}\text { Sub- } \\
\text { categorías }\end{array}$ & \multicolumn{1}{|c}{ Descriptor } \\
\hline \multirow{5}{*}{$\begin{array}{l}\text { Otras operaciones } \\
\text { discursivas que } \\
\text { distorsionan la realidad }\end{array}$} & $\begin{array}{l}\text { Inventar sucesos, objetos o personas que no son tales para deformar o alterar } \\
\text { el mensaje central del relato. Esta operación tiene como único fin añadir } \\
\text { distractores que limiten la capacidad crítica del lector o que garanticen la } \\
\text { visibilización de la interpretación hegemónica en el discurso. }\end{array}$ \\
\hline & $\begin{array}{l}\text { Entregar información incompleta, contradictoria o difusa sobre los procesos } \\
\text { narrados. Esta distorsión busca disfrazar una realidad difícil de esconder } \\
\text { o proporcionar una etiqueta que brinde alguna razón explicativa para } \\
\text { vislumbrar una posible justificación o evasión de responsabilidades frente a } \\
\text { hechos controvertidos y antiéticos. }\end{array}$ \\
\cline { 2 - 2 } $\begin{array}{l}\text { Desviar la atención hacia otro acontecimiento, personaje, lugar u objeto } \\
\text { mediante la técnica del diluvio o inundación de continuas distracciones y de } \\
\text { informaciones insignificantes. Esta estrategia impide al lector interesarse por } \\
\text { hechos controvertidos, temáticas relevantes o cuestiones socialmente vivas. }\end{array}$ \\
\cline { 2 - 3 } $\begin{array}{l}\text { Pretender la neutralidad en el discurso para evitar la entrega de información } \\
\text { interpretativa y significativa que permita al lector formarse un juicio } \\
\text { razonado y fundamentado sobre los hechos narrados. }\end{array}$ \\
\hline
\end{tabular}

Fuente: elaboración propia (2019).

sivas que distorsionan la realidad se sustentan en el método histórico discursivo y en los postulados de Jurjo Torres.

Estas categorías permitieron analizar las representaciones de las mujeres presentes en los libros de la muestra, posibilitando la identificación de relaciones de dominación y resistencia entre distintos grupos y la comprensión del androcentrismo como un eje transversal contenido en el relato pedagógico. En esta línea, el análisis discursivo resulta indispensable para entender la forma en la que el abuso de poder y las desigualdades se representan, reproducen, legitiman y resisten en el texto dentro de los contextos socioculturales (Fairclough, 2013; Van Leeuwen, 2014; Pérez, 2016; Van Dijk, 2019). Siguiendo este enfoque y, a partir de las categorías previstas, esta investigación busca responder a la pregunta: ¿Cuáles son las representaciones discursivas que se proyectan de las mujeres en los textos escolares que abordan la historia de Chile desde 1810 hasta el 2017?

\section{RESULTADOS Y DISCUSIÓN}

Con el fin de responder a la pregunta señalada, se analizan todas las categorías de la Tabla 2 de forma conjunta, describiendo y presentando evidencias (citas, imágenes, representaciones, caracterizaciones, entre otras) de los textos consignados para cada una de ellas. Este análisis hermenéutico sigue un criterio cronológico que comprende desde 1810 hasta el año 2017. 


\section{CHILE REPUBLICANO DEL SIGLO XIX}

Esta etapa comprende desde la Primera Junta Nacional de Gobierno de 1810 hasta 1900, año del cambio de siglo. Durante este periodo, destaca el uso de ciertas operaciones que distorsionan la realidad y que contribuyen a desviar la atención del lector hacia otros personajes o acontecimientos. En el proceso de independencia, por ejemplo, resalta la relevancia histórica categorizada que se le atribuye a distintas mujeres, ya que, siguiendo a Van Leeuwen (1996) y a Minte y González (2015), solo son reconocidas en función de las relaciones de parentesco que tienen con grandes próceres de la patria.

Dentro de dicha categoría, el caso de Javiera Carrera es muy emblemático. El manual de $6^{\circ}$ básico de 2015 aborda el periodo independentista denominado "Patria Vieja" (1810-1814), donde describe el rol de los hermanos Juan José y José Miguel Carrera. De Javiera Carrera solo se limita a decir que "alentó y apoyó esta causa, teniendo una gran influencia como asesora y consejera de sus hermanos y del círculo patriota que los rodeaba" (Fernández y Giadrosić, 2015b, p. 178). Este extracto, además de posicionar a Javiera Carrera en el trasfondo del discurso y de presentarla como la "hermana de...", se focaliza exclusivamente en destacar su rol dentro de la historia patria, ignorando, de esta manera, su vida más íntima y cotidiana. De esta forma, el discurso pedagógico inserto en el texto tiende a desviar la atención hacia los hermanos Carrera, contribuyendo a restar importancia al papel asumido por Javiera Carrera en la historia chilena.

Al igual que el caso de Javiera Carrera, la vida de Paula Jaraquemada también aparece restringida al ámbito de la historia patria, tal como se evidencia en un cuadro de información complementaria ubicado al final de la página 60 del libro de $6^{\circ}$ básico de 2012 (Figura 1).

Paula Jaraquemada: heroína chilena que prestó servicios a la patria en los momentos previos a la culminación de la Independencia. Encontrándose en su hacienda de Paine, recibió al ejército que venía en retirada tras ser derrotado en Cancha Rayada (1818), y le proporcionó los enseres necesarios para su reorganización. Llegado el jefe de la expedición, el general José de San Martín, y al ver la actitud tan generosa de doña Paula, aceptó convertir dicha hacienda en cuartel general de sus tropas. Los realistas, al tener noticia de que la hacienda era refugio de los patriotas, enviaron una patrulla a cargo de un oficial, quien al enfrentarse a doña Paula le exigió las llaves de la bodega, a lo que ésta se negó, exponiendo su vida. Ante tal acto de valentía, la patrulla enemiga emprendió la retirada.

Figura 1 - Cuadro biográfico de Paula Jaraquemada.

Fuente: Álvarez y Barahona (2012, p. 60). 
Uno de los aspectos más relevantes de este recuadro es la visión idealizada que expone a Paula Jaraquemada como una "mujer abnegada" que busca resguardar a las tropas de José de San Martín en su hacienda de Paine. Este sesgo, propio de la historia patria, tiene como objetivo presentar a las mujeres como asesoras o proveedoras de refugio de los grupos independentistas. Al respecto, como sostienen Gómez, Rodríguez y Miralles (2015), es importante tener en cuenta que el conocimiento de la historia patria ha servido para afianzar ideológicamente la legitimidad del poder, así como también para cimentar y estimular el patriotismo de los ciudadanos. Esta función patriótica de la asignatura no ha dejado de existir porque los gobiernos chilenos siguen presionando a la escuela, a través del curriculum escolar, para que continue asumiendo este rol en el proceso de construcción nacional.

Dicha mirada de la historia, siguiendo a Gómez y Chapman (2017), es altamente contraproducente con los nuevos lineamientos didácticos de la disciplina que tienen la pretensión de desarrollar el pensamiento histórico en el alumnado, puesto que impide promover diversos aprendizajes de segundo orden como la empatía histórica, el uso correcto de fuentes, la dimensión ética y la temporalidad.

Además del sesgo patriótico observado, también se destaca el caso de representaciones generalizadas. Por ejemplo, el manual de $6^{\circ}$ básico de 2013 señala: "Las mujeres estuvieron presentes en todo el proceso de independencia. Según el censo de 1813, en el país predominaban las mujeres y una mayoría abrazaba la causa patriota, participando con la misma valentía, sacrificio, tenacidad y valor que los hombres" (Álvarez y Barahona, 2013, p. 54).

Del texto, vale la pena distinguir dos cuestiones relevantes: por una parte, utiliza el plural "las mujeres" para suprimir las identidades y los liderazgos de las participantes que contribuyeron al proceso de emancipación; y por otra, se limita a relacionar el rol de la mayoría de las mujeres con la causa patriota.

Durante el periodo de independencia, sobresalen también algunos casos de exclusión parcial. En el texto de $6^{\circ}$ básico de 2015, dentro del apartado "Reconquista o restauración monárquica (1814-1817)”, se precisa que varias mujeres, entre ellas Paula Jaraquemada, Javiera Carrera, Luisa Recabarren, Cornelia Olivares y Agueda Monasterio, aportaron a la lucha libertaria; sin embargo, no se señala en que consistió su participación (Fernández y Giadrosić, 2015b, p. 180).

Otro caso de exclusión parcial del mismo periodo se relaciona con el tratamiento asignado a Isabel Riquelme. Una evidencia relevante se observa en un recuadro sobre la biografía de Bernardo O'Higgins que aparece en el manual de $6^{\circ}$ básico de 2013 (Figura 2).

Al examinar la biografía de dicho personaje, se resalta el complejo vínculo entre él y su padre Ambrosio O'Higgins, quien es identificado con su nombre y destacado por su sobresaliente carrera en la institucionalidad colonial. En cambio, la referencia que se hace sobre el lazo entre O'Higgins y su madre Isabel Riquelme es bastante sucinto, ya que esta última no es identificada con su nombre ni reconocida por su rol histórico propio. Por otra parte, se constata que el recuadro omite información que puede ayudar a despertar el interés por la historia, como, por ejemplo, 


\section{Una pequeña biografía}

Bernardo O'Higgins Riquelme nació en una familia aristocrática de Chillán. Su padre fue un importante funcionario de la corona española, intendente de Concepción y gobernador del reino de Chile, el irlandés Ambrosio O'Higgins. Su madre, una mujer joven, lo envió a Talca para que fuera protegido y educado por unos tíos. A la edad de 11 años se reencontraría con su progenitora.

La relación con su padre fue muy compleja, por un lado llena de admiración; por otra, plena de distancia y de temor. Siendo su padre gobernador lo envió al Perú para que estudiase en el prestigioso "Convictorio San Carlos". Luego lo mandó a Inglaterra a completar sus estudios. Sus contacto con las ideas antimonárquicas los enemistaron definitivamente, por lo que Bernardo quedó solo y sin un peso.

Volvió a Chile, se hizo cargo de la hacienda familiar y se involucró en el proceso emancipador, logrando ser elegido diputado en el primer Congreso Nacional.

Figura 2 - Cuadro biográfico de Bernardo O'Higgins.

Fuente: Álvarez y Barahona (2013, p. 56)

la gran diferencia de edad que existía entre los padres de Bernardo O'Higgins, pues al momento de su nacimiento, Isabel tenía 19 y Ambrosio 58.

En la segunda mitad del siglo XIX, se abordan diversos avances legislativos que cimentaron los distintos procesos de reivindicación femenina que se desarrollaron en las décadas posteriores. En el contexto de la legislación educacional, se suprime la relevancia histórica y los efectos del Decreto Amunátegui de 1877 en el acceso de la mujer a la educación superior. Por ejemplo, el manual de $2^{\circ}$ medio de 2009 señala que "durante la década de 1870, los avances legales continuaron con el Decreto Amunátegui (1877), que permitió el acceso de las mujeres a la universidad" (Méndez et al., 2009, p. 228).

En dicho texto, no se mencionan los principios y argumentos de la normativa que permiten visualizar su relevancia histórica, tales como: la arraigada creencia de que las mujeres poseían ventajas naturales para ejercer algunos oficios relacionados con la asistencia a terceros; la importancia de ayudar a estas para que tuvieran la posibilidad de generar su propio sustento; y las garantías necesarias para que las mujeres obtuvieran los títulos profesionales bajo las mismas 
condiciones a las que estaban sometidos los hombres. Tampoco se señalan los efectos de este decreto, ya que, gracias a este, varias figuras femeninas pudieron graduarse de la carrera de medicina y derecho. Al respecto, cabe mencionar que las primeras médicas fueron Eloísa Díaz (1887) y Ernestina Pérez (1887); y las primeras abogadas chilenas fueron Matilde Throup (1892) y Matilde Brandau (1898).

Durante la segunda mitad del siglo XIX, también destaca el contexto de la Guerra del Pacífico (1879-1884) porque se evidencia el tratamiento de mujeres bajo la consigna de representaciones generalizadas y de roles pasivos. Por ejemplo, en un manual de $6^{\circ}$ básico, se señala: "También hubo mujeres que jugaron un rol activo en la guerra, participando desde sus hogares de una manera más bien anónima, pero no por ello menos significativa; fueron costureras, hilanderas, lavanderas y enfermeras, atendiendo diversos tipos de necesidades militares" (Álvarez y Barahona, 2013, p. 110).

Del párrafo, se constatan tres aspectos fundamentales: en primer lugar, emplea la frase "las mujeres" para omitir el nombre y el rol de las participantes en la Guerra del Pacífico; en segundo lugar, entrega información contradictoria sobre los hechos, pues si bien sostiene que las mujeres tuvieron un papel activo en el conflicto, no señala a ninguna realizando una acción concreta; y, en tercer lugar, restringe a las mujeres al ámbito doméstico, ya que precisa que se limitaron a ser costureras, hilanderas y lavanderas. En esta línea, como señala Stuven (2014), es fundamental notar que se omiten importantes figuras femeninas de la Guerra del Pacífico, tales como Irene Morales (mujer soldado que colaboró en la batalla de Dolores) y Filomena Valenzuela (destacada soldado que participó en el asalto a Pisagua y que alcanzó el grado de subteniente).

En los años posteriores a la Guerra del Pacífico, se observa el uso reiterado de opciones léxicas que tienden a la representación generalizada de las mujeres, lo que, según Van Leeuwen (1996), conlleva a concebir su actuación de forma colectiva y anónima. El libro de $1^{\circ}$ medio de 2016, por ejemplo, dedica, al final de la lección 1 de la Unidad II "La construcción del Estado-nación y sus desafíos", un apartado llamado "Distintas visiones" para hablar acerca del rol de las mujeres en el siglo XIX. Allí se exponen dos extractos que presentan las visiones de la historiadora Guadalupe Gómez-Ferrer y de la investigadora Anne-Marie Käppeli sobre esta temática (Figura 3).

Los párrafos citados presentan un alto nivel de abstracción y tienden a ser muy generales, lo que impide identificar a las participantes y asociarlas con los procesos históricos, que suelen ser tratados desde una óptica eurocéntrica. Como señala Mary Nash (2002), esta perspectiva se está profundizando en la actualidad debido a los diversos estudios, principalmente estadounidenses como los de Flax (1995) y de Butler (2001), que insisten en la reivindicación femenina dentro de la blancura y contexto europeo de modernidad.

Otro rasgo interesante se registra en una fotografía de las inglesas Annie Kenney y Christabel Pankhurst que aparece en un texto de $1^{\circ}$ medio (Figura 4). Si bien Kenney y Pankhurst tienen una representación específica en dicha imagen, no precisa el rol activo que tuvieron en la lucha del voto femenino en el Reino Unido, 
Es bueno tener presente que en el pensamiento liberal, junto con la virtud política y la "ética de la justicia" masculina y pública por definición, hay otra virtud a la que no se le da menos importancia: la "ética del cuidado", que se practica en el ámbito doméstico y se fundamenta "en unos valores que se consideran propios de las mujeres: el amor, la paciencia, la discreción, la laboriosidad (...); valores reforzados y difundidos en los textos normativos, religiosos y literarios de la época".

Desde esta perspectiva se ha de plantear cómo se configuró la identidad femenina a partir de dos tipos de discursos. Por una parte, los que provenían del ámbito político, jurídico, educativo, médico, religioso y moral, que venían a prescribir la ausencia de las mujeres en los marcos de la vida pública, y servian para regular su comportamiento. Y por otra, los que procedían de círculos minoritarios, femeninos casi en exclusiva, que buscaban denunciar la discriminación social, civil o política que padecían las mujeres.

Gómez-Ferrer, G. Historia de las mujeres en España: siglos XIX y XX. Cuadernos de Historia 114. Madrid, España: Arco Libros, 2011.
En el siglo XIX, un grupo minoritario de mujeres se crearon una identidad pública a través del feminismo, tanto por medio de la escritura como por sus talentos organizativos. Estas mujeres entran en escena blandiendo por su cuenta la Declaración de los Derechos del Hombre (...). Gracias a cambios de legislación, se les reconoce su condición civil. Las sufragistas anunciaban una nueva identidad política. Al romper el silencio que rodeaba su sexualidad, abogan por una nueva moral. Su lucha por el acceso al mundo profesional sienta las bases indispensables para la conquista de la autonomía económica.

Kàppeli, A. Escenarios del feminismo. En Duby, G. y Perrot, M. Historia de las Mujeres. Tomo 4. Buenos Aires, Argentina: Taurus, 2000.

Figura 3 - Extractos de la historiadora Guadalupe Gómez-Ferrer y de la investigadora Anne-Marie Käppeli sobre las mujeres en el siglo XIX.

Fuente: Morales et al. (2016, p. 93).

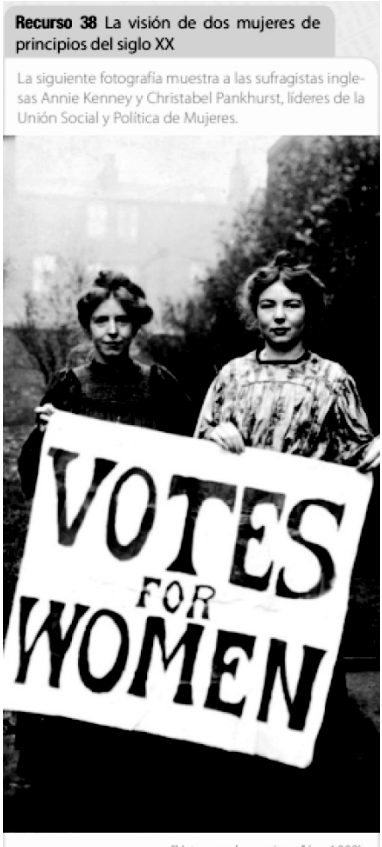

"Voto para las mujeres"(ca. 1908).

Figura 4 - Fotografía de las inglesas Annie Kenney y Christabel Pankhurst, líderes de la Unión Social y Política de Mujeres.

Fuente: Morales et al. (2016, p. 92). 
ni tampoco se destaca su protagonismo como precursoras o referentes del proceso sufragista que lideraron las mujeres chilenas a partir de 1930.

\section{CHILE EN EL SIGLO XX Y XXI}

Esta etapa comprende desde 1900 hasta el 2017, año de publicación del manual más reciente de la muestra analizada. Durante este periodo, se evidencia la mayor parte de las categorías descritas en la Tabla 2.

En el contexto del auge salitrero que se extendió desde finales del siglo XIX hasta el año 1920, se constata la representación generalizada de mujeres y el uso de operaciones discursivas que distorsionan su rol social. Por ejemplo, en un manual de $2^{\circ}$ medio, se precisa que:

Las mujeres se desempeñaban como cocineras, costureras, lavanderas y empleadas en las casas de la gente acomodada o trabajaban en las pulperías. Para obtener algún tipo de ingreso muchas debieron recurrir al comercio sexual deambulando por las oficinas o en los puertos de embarque del salitre: Iquique, Tocopilla o Antofagasta. (Mendizábal y Riffo, 2013, p. 262)

Si bien el párrafo citado se encuentra en la parte central del texto, el uso del plural "las mujeres" y el predominio del discurso de la domesticidad, que restringe y naturaliza el rol de la mujer a las labores del hogar, tienden a suprimir la identidad y el papel de las agentes sociales. De igual modo, siguiendo a Montecino (2008) y a Llorca y Barría (2017), excluye totalmente la participación de mujeres destacadas durante el periodo del auge salitrero, tales como Juana Ross (gran filántropa chilena que construyó y mantuvo tres hospitales, seis asilos, un hospicio, un orfanato e infinidad de escuelas), Eloísa Díaz (primera médica de Chile y de América del Sur) y Ernestina Pérez (destacada activista femenina y segunda médica de América Latina).

En la década de los veinte, se describen diversos procesos que contribuyeron a modificar la posición de las mujeres en la sociedad y que fueron resultado de la acción de los movimientos sociales que ellas mismas lideraron. Por ejemplo, en un apartado titulado "Formación Docente", que trata sobre la formación profesional de los profesores y sus respectivos conflictos laborales, se precisa: "Las inadecuadas condiciones laborales y de remuneración fueron focos periódicos de conflicto. A diferencia de otras profesiones de la época, el cuerpo docente estaba constituido en gran parte por mujeres"(Quintana et al., 2012, p. 119).

Dicho párrafo, además de relacionar explícitamente el rol de las mujeres con ciertas profesiones, no precisa la relevancia histórica de las docentes durante el periodo y no menciona, como sostiene Vera (2015), el papel desempeñado por grandes maestras como Amanda Labarca (primera mujer que alcanzó la titularidad de una cátedra universitaria en 1922) e Isaura Dinator de Guzmán (primera mujer miembro del Consejo de Instrucción Pública en 1925).

Entre los años treinta y cincuenta, se alude a procesos similares como, por ejemplo, la creciente cobertura del sistema educacional, el ingreso de las mujeres al campo laboral y la conquista de los derechos ciudadanos. "La lucha femenina organizada se abrió paso y, progresivamente, consiguió enormes logros en el ámbito 
público, como el acceso al sufragio en todos los comicios. En 1935 votaron por primera vez en elecciones municipales y en 1952 en las presidenciales" (Quintana et al., 2012, p. 107).

El texto citado reconoce el rol de las mujeres en el logro del sufragio femenino; sin embargo, el uso de la frase "lucha femenina" suprime las identidades, tanto de las organizaciones como de las líderes del movimiento social. En esta línea, como señala Grez (2011) y Torres (2015), es indispensable indicar que ignora a importantes colectivos organizados que contribuyeron al proceso reivindicativo de las mujeres, tales como los Centros Femeninos Belén de Zárraga, vinculados a mujeres de clase obrera, el Club Social de Señoras, conformado por mujeres de la aristocracia, y los Círculos de Lectura, integrados por mujeres laicas de clase media.

Siguiendo a Stuven (2014), también excluye el rol activo que asumieron los primeros partidos políticos femeninos de Chile como el Partido Cívico Femenino (1922), el Partido Demócrata Femenino (1924) y el Partido Femenino Chileno (1946), y diversas asociaciones como el Movimiento Pro Emancipación de la Mujer Chilena (MEMCH), que se dedicó a abordar la situación de la mujer en forma integral, desde la igualdad jurídica y política hasta el acceso al mercado laboral, y la Federación Chilena de Instituciones Femeninas (FECHIF), que fue una pieza clave en el movimiento que propició la promulgación de la ley que autorizó el voto femenino en las elecciones parlamentarias y presidenciales. Suprime, asimismo, el liderazgo de las principales dirigentes que han sido reconocidas históricamente tanto por su calidad de feministas pioneras como por sus trayectorias en el ámbito político e intelectual, tales como Elena Caffarena, Olga Poblete, Marta Vergara y Graciela Mandujano.

Un párrafo similar al citado anteriormente se observa en el texto de $2^{\circ}$ medio de 2017. "En 1935 se reconoció el voto femenino en las elecciones municipales, y en 1952 las mujeres pudieron participar en las presidenciales" (Honeyman et al.,2017, p. 107). Además de exponerlas en un segundo plano, el discurso tiende a reforzar el tratamiento pasivo de las mujeres al no concebirlas como sujetos activos en la conquista del sufragio universal y en la construcción de una democracia más justa y representativa. Al respecto, y siguiendo a Fairclough (2003), resulta conveniente subrayar que los actores sociales tienen un rol activo cuando tienen capacidad autónoma para desarrollar acciones o liderar procesos; y cuando son representados de forma pasiva, como en el ejemplo anterior, se remarca su condición de subordinación o anonimato en el contexto de los procesos históricos.

Un rasgo similar al de la evidencia previa se observa en el siguiente texto:

La situación de las mujeres cambió durante la primera mitad del siglo XX. Se incorporaron de manera creciente al mercado laboral, se integraron de forma masiva en la educación primaria y secundaria, se impusieron como agentes culturales de primera línea y conquistaron la totalidad de los derechos políticos. (Quintana et al., 2012, p. 124)

En este extracto, el uso de las expresiones "las mujeres" y "agentes culturales" conlleva una supresión de liderazgos de los grupos y de las mujeres que encabezaron 
el movimiento social. Por otra parte, en los términos de Torres (1998), hay una asignación contradictoria de roles en la reivindicación de los derechos conquistados por las mujeres. En un primer momento, los autores del manual escolar las conciben bajo una representación generalizada y pasiva, pero luego son "activadas" cuando señalan que "se impusieron como agentes culturales de primera línea y conquistaron la totalidad de los derechos políticos" (Quintana et al., 2012, p. 124).

En la primera mitad del siglo XX, aunque la mayoría de las mujeres son tratadas desde la consigna de representaciones generalizadas, se constata que también hay algunas que aparecen nominadas, pero siempre en el trasfondo del discurso. Figuran, por ejemplo, en los apéndices algunos nombres como el de Amanda Labarca y Elena Caffarena (Quintana et al., 2012, p. 124-125). En apéndices o cuadros marginales, también aparecen imágenes donde se presentan a mujeres en diferentes situaciones y que son identificadas con las siguientes referencias: "Obreras textiles", "Retrato de un matrimonio y sus hijos, 1920" y "Mujer conduce un automóvil, 1930" (Figura 5). Esta forma de representación, siguiendo el modelo de Fairclough (2003), distancia a las mujeres de los procesos históricos, ya que utiliza un elevado nivel de abstracción para exponerlas como figuras que están al margen de los acontecimientos.

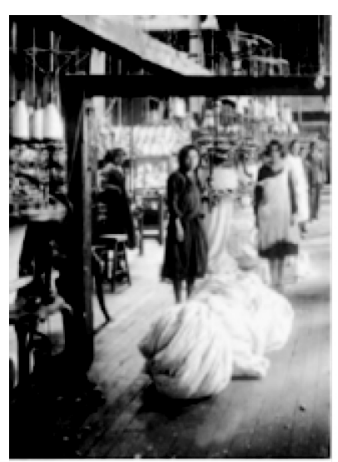

$\Delta$ Otreras textles

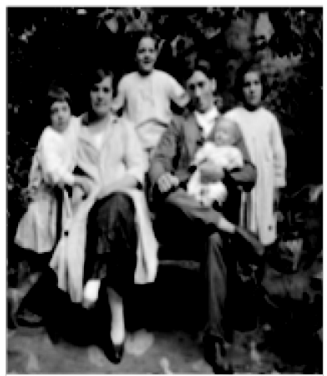

4 Retato de un matrinonio y sas hisos, 1920

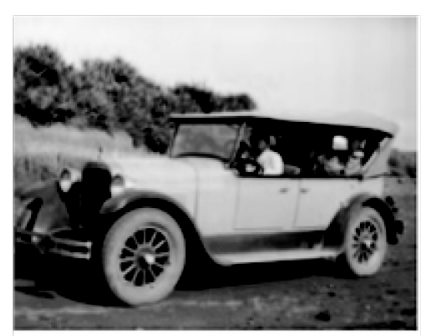

A. Mujer conduce un automóvil, 1930

Figura 5 - Fotografías de mujeres chilenas de la primera mitad del siglo XX.

Fuente: Quintana et al. (2012, p. 124-126).

Para Fernández (2010), la presencia de mujeres en apéndices o recuadros apartados del discurso central aumenta el riesgo de que el lector no considere a las figuras allí representadas o no les asigne la importancia requerida, o bien que no sea capaz de comprender su relevancia en los procesos históricos abordados en el resto del texto.

Desde la segunda mitad del siglo XX en adelante, se continúa utilizando la representación generalizada para disminuir o suprimir parcialmente la participación femenina en la historia. Por ejemplo, en el ámbito del desabastecimiento producido a fines de 1972 durante el Gobierno de la Unidad Popular, un texto de $3^{\circ}$ medio señala: "Para protestar en contra de los primeros indicios de desabastecimiento, en 
diciembre se produjo la primera de las 'marcha de las cacerolas', en las que mujeres de clase alta y media hicieron sonar utensilios de cocina"(Quintana et al.,2012, p. 169).

En el párrafo extraído, se evidencia explícitamente el discurso de la domesticidad porque en el contexto de la "marcha de las cacerolas" tiende a normalizar y asociar la acción de las mujeres con el sonido de los utensilios de cocina, ignorando, de esta manera, la actuación de hombres en estas protestas. Igualmente, cabe señalar que no se precisa el nombre de mujeres que participaron en estas movilizaciones, ni el impacto que generaron a posteriori. En esta línea, como sostiene Roitman (2019), el texto no relaciona el surgimiento del Poder Femenino con la "marcha de las cacerolas", ni identifica a las grandes protagonistas de tales manifestaciones como María Correa (escritora y diputada entre 1957 y 1961), Carmen Saenz (agricultora y política) y Teresa Maillet (presidenta nacional de las mujeres democratacristianas).

Un rasgo similar se expone en los manuales que abordan el acceso de la mujer al mercado laboral desde los años sesenta en adelante. Como referente, se destaca el siguiente párrafo:

Un factor importante en el último siglo, y particularmente en los últimos 50 años en Chile, ha sido la incorporación de la mujer al trabajo, aspecto que influye en el mercado del trabajo, ya que ellas constituyen una nueva fuerza laboral que compite frente a la disponibilidad de puestos de trabajo. (Latorre, Henríquez y Rocha, 2013, p. 228)

Si bien el texto reconoce la relevancia histórica de la incorporación de la mujer al trabajo, no específica las causas, los problemas y la repercusión posterior de este hito, pues lo presenta con un elevado nivel de abstracción. En efecto, como sostiene Stuven (2014), no se explica la relación que tiene dicho proceso con la creciente industrialización del país ni con el proceso reivindicativo que lideraron diversas mujeres como Eloísa Diaz, Amanda Labarca y Gabriela Mistral desde finales del siglo XIX para posicionar el rol femenino en la sociedad. Asimismo, siguiendo a Díaz et al. (2017), tampoco menciona los graves problemas que todavía persisten en el mundo laboral femenino, como el acoso sexual, la desigualdad salarial y la normalización de ciertos trabajos "reservados" para mujeres.

Otro caso que resalta es la utilización de operaciones discursivas que buscan la neutralidad en el discurso pedagógico. Por ejemplo, en el libro de $1^{\circ}$ medio de 2016, al final de la lección 3 de la Unidad IV "La configuración del territorio chileno y sus proyecciones", dedica un apartado llamado "Del pasado al presente" para hablar sobre la evolución del rol de la mujer mapuche a lo largo de la historia. Si bien el texto reconoce las diferencias de determinados roles sociales según el género, expone una visión general y que aspira a la imparcialidad discursiva al afirmar que en "el mundo mapuche tradicional, hombres y mujeres tenían claramente determinadas sus funciones en cuanto a tareas domésticas, de subsistencia y de trascendencia, es decir, la transmisión de saberes, cultura, ritos, entre otros"(Morales et al., 2016, p. 236).

De acuerdo con esto último, es importante destacar que uno de los grandes objetivos de los productores de los textos escolares en los últimos años ha sido imponer una visión "neutral" de la historia. Este rasgo también se aprecia en el siguiente cuadro sobre el femicidio: 
En el cuadro citado (Figura 6), que aparece al lado izquierdo del discurso central, se observan tres cuestiones relevantes: en primer lugar, presenta una definición sucinta y que busca conceptualizar el término de femicidio desde un posicionamiento "neutral" porque no precisa las causas del mismo ni lo desarrolla en base a una perspectiva problematizadora; en segundo lugar, si bien reconoce que se han liderado políticas públicas para concientizar a la población sobre el femicidio, no menciona ningún ejemplo y tampoco específica el trasfondo histórico del problema; por último, solo se limita a señalar que el principal resultado de tales políticas es el descenso progresivo del número de asesinatos de mujeres, ignorando, entre otros aspectos, las dificultades y los desafíos que prevalecen en estas medidas para avanzar hacia una mayor igualdad de género.

\begin{tabular}{|c|c|}
\hline \multicolumn{2}{|c|}{$\begin{array}{l}\text { El femicidio se entiende como el asesinato de } \\
\text { mujeres por el hecho de ser tales. Supone ur } \\
\text { conjunto de prácticas, órdenes y representa- } \\
\text { ciones simbólicas que se sostienen en el su- } \\
\text { puesto de inferioridad de la mujer. }\end{array}$} \\
\hline \multicolumn{2}{|c|}{$\begin{array}{l}\text { Por mucho tiempó este problema fue catalo } \\
\text { gado dentro del ámbito privado, pero desde } \\
\text { hace una década fue colocado en la agenda } \\
\text { pública de los gobiernos, los que mediante } \\
\text { diversas politicas públicas han intentado con- } \\
\text { cientizar a la población. }\end{array}$} \\
\hline \multicolumn{2}{|c|}{$\begin{array}{l}\text { Los resultados de estas politicas se pueder } \\
\text { apreciar, entre otras posibilidades, en las si } \\
\text { guientes cifras: }\end{array}$} \\
\hline \multicolumn{2}{|c|}{$\begin{array}{c}\text { Femicidios en Chile desde } 2009 \text { a } 2012 \\
\text { (Total nacional) }\end{array}$} \\
\hline Año & Casos \\
\hline 2009 & 55 \\
\hline 2010 & 49 \\
\hline 2011 & 40 \\
\hline 2012 & 34 \\
\hline
\end{tabular}

Figura 6 - Femicidios en Chile desde 2009 a 2012.

Fuente: Latorre, Henríquez y Rocha (2013, p. 102).

Por añadidura, también cabe notar que los textos escolares que tratan sobre los recientes proyectos para empoderar a las mujeres se basan en un discurso que aspira a la neutralidad. Por ejemplo, en un manual de $4^{\circ}$ medio, se precisa que:

Los diagnósticos han apuntado a fortalecer a los sectores más vulnerables de la población, vale decir, mujeres y jóvenes; de esa manera ha habido diversos proyectos, en distintas partes del mundo, para empoderar a las mujeres. Con 
este propósito se creó en el año 2010 la ONU Mujer, que tuvo como primera secretaria a la presidenta de Chile, Michelle Bachelet. (Latorre, Henríquez y Rocha, 2013, p. 130)

Este párrafo, al igual que las dos evidencias anteriores, se basa en una pretensión de imparcialidad discursiva que conlleva una evasión de responsabilidad por parte de los productores escolares porque dentro de este posicionamiento, en los términos de Fairclough y Wodak (2019), no tienen la necesidad de explicar sus afirmaciones desde una mirada problematizadora. Esta situación se contradice con las bases epistémicas del pensamiento histórico, especialmente con el aprendizaje de segundo orden relacionado con el carácter hermenéutico de la historia y que es necesario enseñar al alumnado para que pueda visualizar la utilidad social de dicha disciplina en la vida cotidiana. Para lograr este objetivo, siguiendo a Rivera y Mondaca (2013), es de vital importancia promover un rol docente activo, basado en el currículum oculto y en un compromiso social que recupere el papel de sujeto reflexivo y transformador, para combatir la pereza e incluso el miedo de la comodidad neutra que aparece en muchos profesores al abordar metodológicamente el estudio de la historia reciente desde la óptica descriptiva y mínimamente interpretativa.

En el periodo actual, también se recurre al uso de operaciones discursivas que tienden a entregar información incompleta sobre los procesos todavía vigentes, especialmente aquellos relacionados con la evolución de la estructura demográfica de los últimos 20 años. Por ejemplo, el manual de $3^{\circ}$ medio de 2013, restringe el rol de la mujer en el contexto de la maternidad y crianza, pues al señalar que "la mayor incorporación de las mujeres a trabajos fuera del hogar, entre otros factores, hicieron que el crecimiento de la población disminuyera" (Latorre, Henríquez y Rocha, 2013, p. 285) relaciona exclusivamente el creciente acceso de la mujer al mercado laboral con las menores tasas de natalidad, descartando, de esta forma, la prevalencia de otros antecedentes como la ampliación del derecho a la educación, los cambios en la composición familiar y las implicaciones de la sociedad de consumo en el presupuesto del hogar.

\section{CONCLUSIÓN}

$\mathrm{El}$ análisis discursivo de los textos e imágenes presentes en los manuales escolares revisados permite constatar el uso de diferentes convenciones como la supresión, la exclusión parcial, la relevancia histórica categorizada, la asignación de roles pasivos, la representación generalizada y la pretensión de mostrar una visión "neutral" de la historia, que tienen como único propósito ocultar o atenuar la importancia de la participación femenina en la historia republicana chilena.

Las mujeres que suelen aparecer con mayor recurrencia en el periodo decimonónico son Javiera Carrera y Paula Jaraquemada, y en el siglo XX, Amanda Labarca y Elena Caffarena son las que tienen más presencia en el discurso. No obstante, cabe destacar que estas no figuran en la totalidad de los textos y que no todas son representadas de igual modo porque tienden a ser marginadas o desplazadas por las diferentes convenciones mencionadas. También resulta indispensable mencionar 
que es frecuente el uso de generalizaciones para omitir la identidad y los liderazgos que tuvieron distintas mujeres en la historia de Chile, tales como Irene Morales, Isaura Dinator, María Correa, Carmen Saenz y Teresa Maillet. Se destaca, asimismo, la pretensión de imparcialidad discursiva de los textos que buscan proyectar una lectura descriptiva y escasamente interpretativa sobre los hechos analizados, con el fin de eludir la entrega de información significativa y crítica que permita al lector cuestionar el discurso hegemónico de la historia escolar.

De esta manera, el encubrimiento de la mujer realizado en los textos escolares de Historia, Geografía y Ciencias Sociales ha buscado construir e imponer una sociedad patriarcal, donde la marginación de las figuras femeninas se presenta como un rasgo normalizado y extendido en el curriculum nacional. Esta situación configura una memoria incompleta sobre las mujeres que han contribuido a la consolidación nacional del país y transmite estereotipos de género que anulan la posibilidad de concebir un relato capaz de resignificar la posición histórica y social de las mujeres.

Este posicionamiento responde a los lineamientos curriculares de Zig-Zag, Santillana y SM. Estas empresas, que concentran el mercado editorial chileno, se rigen por una perspectiva androcéntrica de la historia que considera el enfoque masculino como medida de todas las cosas y generaliza esos resultados como verdades universales; y a su vez, restringe el rol femenino a la reproducción de seres humanos, a la generación de bienes de consumo familiar y a todo aquello que forma parte del entorno doméstico. Debido a este sesgo, es importante que los profesores estén conscientes de tal situación y así puedan cuestionar, en perspectiva histórica, los textos escolares al momento de enseñar la asignatura a sus alumnos, lo que, sin duda, disminuirá el potencial riesgo de transmitir creencias que contribuyan a negar la importancia de la mujer en la sociedad.

Para emprender esta acción pedagógica, se sugieren tres lineamientos. En primer lugar, es indispensable democratizar el curriculum para no seguir replicando el paradigma androcéntrico en los textos escolares o en el aula y contribuir a privilegiar un enfoque histórico crítico y reflexivo que valore a las mujeres como actores sociales capaces de transformar o resistir a los imaginarios o discursos impuestos por el mundo masculino. En segundo lugar, resulta recomendable promover el pensamiento histórico en los estudiantes, con el fin de que puedan analizar la historia como un conocimiento problematizador y hermenéutico que ayude a comprender el rol histórico de la mujer. Esto permitiría eliminar la pretensión de neutralidad discursiva en la enseñanza de la disciplina, a partir del análisis y contraste de fuentes y de la generación de narrativas históricas. En tercer lugar, es imperativo que el Estado pueda modificar sustancialmente las prescripciones curriculares para diseñar los libros de texto, con el propósito de incorporar a aquellas mujeres que han sido invisibilizadas, en todos sus niveles, de la historia republicana de Chile.

Estas medidas, sin duda, ayudarían a contrarrestar las expresiones de discriminación explícita o simbólica contra la mujer que todavía están presentes en la cultura y que no se hacen visibles, entre otros motivos, porque la historia escolar ofrece una versión interesada y distorsionada del pasado. De igual modo, también pueden facilitar y mejorar el proceso de empatía histórica de las niñas y jóvenes mujeres porque les permite comprender que las personas de su género son agentes 
sociales relevantes en la historia y que no son un componente aditivo o dependiente del mundo masculino.

Por último, es fundamental poner de manifiesto la necesidad de proseguir con la realización de nuevas investigaciones que permitan profundizar o plantear nuevas miradas sobre la problemática, con la intención de conseguir que los manuales logren adaptarse a los cambios políticos, sociales, económicos y culturales de las sociedades presentes.

\section{REFERENCIAS}

ÁLVAREZ, G.; BARAHONA, M. Texto del Estudiante de Historia, Geografía y Ciencias Sociales $4^{\circ}$ medio. Santiago de Chile: Zig-Zag, 2010.

ÁLVAREZ, G.; BARAHONA, M. Texto del Estudiante de Historia, Geografía y Ciencias Sociales $6^{\circ}$ básico. Santiago de Chile: Zig-Zag, 2012.

ÁLVAREZ, G.; BARAHONA, M. Texto del Estudiante de Historia, Geografía y Ciencias Sociales $6^{\circ}$ básico. Santiago de Chile: Zig-Zag, 2013.

BALLÉN, M.; PULIDO, R.; ZÚÑIGA, F.Abordaje hermenéutico de la investigación cualitativa: teorías, procesos, técnicas. Bogotá: Universidad Cooperativa de Colombia, 2007.

BUTLER, J. El género en disputa: el feminismo y la subversión de la identidad. México: Paidós, 2001.

CHISHOLM, L. Representations of class, race, and gender in textbooks. In: FUCHS, E.; BOCK, A. (org.). The palgrave handbook of textbook studies. Noeva York: Palgrave Macmillan, 2018. p. 225-237.

CLARK, R. et al. Women of the world, re-write!: women in american world history high school textbooks from the 1960s, 1980s, and 1990s. Social Education, Silver Spring, v. 69, n. 1, p. 41-45, 2005.

DÍAZ, X. et al. Violencia de género en el trabajo en Chile. Un campo de estudio ignorado. Ciencia \& Trabajo, Santiago de Chile, v. 19, n. 58, p. 42-48, 2017. http:// dx.doi.org/10.4067/S0718-24492017000100042

DÍEZ, E. Códigos de masculinidad hegemónica en educación. Revista Iberoamericana de Educación, Madrid, v. 68, n. 68, p. 79-98, 2015. Disponible en: https://rieoei.org/ historico/documentos/rie68a04.pdf. Acceso en: 11 dic. 2019.

DOMÍNGUEZ, J.; LÓPEZ, A.; NIETO, B. Violencia escolar: diferencias de género en estudiantes de secundaria. Revista Complutense de Educación, Madrid, v. 30, n. 4, p. 1031-1044, 2019. https://doi.org/10.5209/rced.59997

FAIRCLOUGH, N. Representations of social events. In: FAIRCLOUGH, N. (coord.). Analysing Discourse. Textual analisis for social research. Nueva York: Routledge, 2003. p. 134-155.

FAIRCLOUGH, N. Language and power. Nueva York: Routledge, 2013. FAIRCLOUGH, N.; WODAK, R. Análisis crítico del discurso. In: VAN DIJK, T. (org.). El discurso como interacción social. Barcelona: Gedisa, 2019. p. 367-404. 
FERNÁNDEZ, C.; GIADROSIĆ, G. Texto del Estudiante de Historia, Geografía y Ciencias Sociales $5^{\circ}$ básico. Santiago de Chile: Ediciones SM, 2015a. FERNÁNDEZ, C.; GIADROSIĆ, G. Texto del Estudiante de Historia, Geografía y Ciencias Sociales $6^{\circ}$ básico. Santiago de Chile: Ediciones SM, 2015b.

FERNÁNDEZ, M. Las mujeres en el discurso pedagógico de la historia. Exclusiones, silencios y olvidos. Universum, Talca, v. 25, n. 1, p. 84-99, 2010. http://dx.doi. org/10.4067/S0718-23762010000100007

FERNÁNDEZ, M. La valoración en el discurso de la enseñanza de la historia. Aportes para el análisis del androcentrismo. Revista Signos, Valparaíso, v. 50, n. 95, p. 361-384, 2017. http://dx.doi.org/10.4067/S0718-09342017000300361

FERNÁNDEZ, M.; BAEZA, P. Androcentrismo en la co-construcción discursiva multimodal crítica de significados valorativos en la enseñanza de la historia. Literatura y Lingüística, Santiago de Chile, n. 38, p. 251-274, 2018. http://dx.doi. org/10.29344/0717621X.38.1636

FLAX, J. Psicoanálisis y feminismo: pensamientos fragmentarios. Valencia: Universidad de Valencia, 1995.

GARCÍA, J. Hacia una escuela libre de sexismo: reflexiones desde el currículo de literatura. Revista de Educación de la Universidad de Granada, Granada, v. 26, p. 109-124, 2019. https://doi.org/10.30827/reugra.v26i0.130

GÓMEZ, C.; CHAPMAN, A. Enfoques historiográficos y representaciones sociales en los libros de texto. Un estudio comparativo, España-Francia-Inglaterra. Historia y Memoria de la Educación, n. 6, p. 319-361, 2017. https://doi.org/10.5944/ hme.6.2017.17132

GÓMEZ, C.; GALLEGO, S. La pervivencia de estereotipos de género en la enseñanza de la historia. Un estudio a través de libros de texto y las percepciones del alumnado de educación secundaria en España. Revista Electrónica Educare, Heredia, v. 20, n. 3, p. 1-28, 2016. https://doi.org/10.15359/ree.20-3.1

GÓMEZ, C.; RODRÍGUEZ, R.; MIRALLES, P. La enseñanza de la Historia en educación primaria y la construcción de una narrativa nacional. Un estudio sobre exámenes y libros de texto en España. Perfiles Educativos, México, v. 37, n. 150, p. 21-38, 2015. Disponible en: http://www.scielo.org.mx/pdf/peredu/v37n150/v37n150a2. pdf. Acceso en: 13 dic. 2019.

GÓMEZ, C.; VIVAS, V.; MIRALLES, P. Competencias históricas y narrativas europeas/nacionales en los libros de texto. Cuadernos de Pesquisa, São Paulo, v. 49, n. 172, p. 210-234, 2019. https://doi.org/10.1590/198053145406

GRANA, I.; LARA, N. La excepción que confirma la regla: la ausencia de mujeres relevantes para la literatura española en los manuales escolares. Ciencia, Técnica y Mainstreaming Social, Valencia, n. 3, p. 13-22, 2019. https://doi.org/10.4995/ citecma.2019.10908

GREZ, S. Historia del Comunismo en Chile. Santiago de Chile: LOM, 2011. HONEYMAN, S. et al. Texto del Estudiante de Historia, Geografía y Ciencias Sociales $2^{\circ}$ medio. Santiago de Chile: Santillana, 2017. 
ISLAM, K.; ASADULLAH, M. Gender stereotypes and education: a comparative content analysis of Malaysian, Indonesian, Pakistani and Bangladeshi school textbooks. PLoS One, San Francisco, v. 13, n. 1, e0190807,2018. https://doi.org/10.1371/journal. pone.0190807

KOSTAS, M. Discursive construction of hegemonic masculinity and emphasised femininity in the textbooks of primary education: children's discursive agency and polysemy of the narratives. Gender and Education, Londres, v. 33, n. 1, p. 50-67, 2021. https://doi.org/10.1080/09540253.2019.1632807

LATORRE, I.; HENRÍQUEZ, M. Texto del Estudiante de Historia, Geografía y Ciencias Sociales $3^{\circ}$ medio. Santiago de Chile: Zig-Zag, 2013.

LATORRE, I.; HENRÍQUEZ, M.; ROCHA, P. Texto del Estudiante de Historia, Geografía y Ciencias Sociales $4^{\circ}$ medio. Santiago de Chile: Zig-Zag, 2013.

LINARES, M. Infórmate, investiga y comunica. Madrid: ACCI, 2019.

LLORCA, M.; BARRÍA, D. Empresas y empresarios en la historia de Chile: 18101930. Santiago de Chile: Editorial Universitaria, 2017.

LLORENT, V.; COBANO, V. La mujer en los libros de texto de bachillerato en España. Cuadernos de Pesquisa, São Paulo, v. 44, n. 151, p. 156-175, 2014. https:// doi.org/10.1590/198053142752

LONDOÑO, D.; BERMÚDEZ, H. Tres enfoques sobre los estudios críticos del discurso en el examen de la dominación. Palabra Clave, Bogotá, v. 16, n. 2, p. 491-519, 2013. Disponible en: http://www.scielo.org.co/pdf/pacla/v16n2/v16n2a10.pdf. Acceso en: 20 dic. 2019.

MÉNDEZ, V. et al. Texto del Estudiante de Historia, Geografía y Ciencias Sociales $2^{\circ}$ medio. Santiago de Chile: Santillana, 2009.

MENDIZÁBAL, M.; RIFFO, J. Texto del Estudiante de Historia, Geografía y Ciencias Sociales $2^{\circ}$ medio. Santiago de Chile: Ediciones SM, 2013.

MINTE, A.; GONZÁLEZ, E. Discriminación y exclusión de las mujeres en los textos escolares chilenos y cubanos de historia. Revista de Investigación Educativa, Murcia, v. 33, n. 2, p. 321-333, 2015. https://doi.org/10.6018/rie.33.2.196231

MONTECINO, S. Mujeres chilenas: fragmentos de una historia. Santiago de Chile: Editorial Catalonia, 2008.

MORALES, J. et al. Texto del Estudiante de Historia, Geografía y Ciencias Sociales $\mathbf{1}^{\circ}$ medio. Santiago de Chile: Santillana, 2016.

MORENO, E. et al. Texto del Estudiante de Historia, Geografía y Ciencias Sociales $\mathbf{1}^{\circ}$ básico. Santiago de Chile: Santillana, 2013.

NASH, M. Los nuevos sujetos históricos: perspectivas de fin de siglo. Género, identidades y nuevos sujetos históricos. In: ROMEO, M.; SAZ, I. (org.). El siglo XX: historiografía e historia. Valencia: PUV, 2002.p. 85-100.

OLIVERA, M. Estudio de uso y valoración de textos escolares. Informe final encargado por el Ministerio de Educación (MINEDUC) y la Oficina Regional de Educación para América Latina y el Caribe (UNESCO). Santiago de Chile: 
Guernica Consultores, 2016. Disponible en: http://biblioteca.digital.gob.cl/bitstream/ handle/123456789/398/Informe\%20Final\%20Uso\%20y\%20Valoracion\%20de\%20 Textos\%20Escolares.pdf?sequence=1\&isAllowed=y. Acceso en: 11 dic. 2019.

PÉREZ, C. La representación visual del movimiento estudiantil chileno en la prensa establecida y alternativa nacional: un análisis multimodal. Revista Austral de Ciencias Sociales, Valdivia, n. 30, p. 5-26, 2016. https://doi.org/10.4206/rev.austral.cienc. soc.2016.n30-01

PINEDO, R.; ARROYO, M.; BERZOSA, I. Género y educación: detección de situaciones de desigualdad de género en contextos educativos. Contextos Educativos, Logroño, n. 21, p. 35-51, 2018. https://doi.org/10.18172/con.3306

QUINTANA, S. et al. Texto del Estudiante de Historia, Geografia y Ciencias Sociales $3^{\circ}$ medio. Santiago de Chile: Ediciones SM, 2012.

RIVERA, P.; MONDACA, C. El aporte de la enseñanza de la historia reciente en Chile: disensos y consensos desde la transición política al siglo XXI. Estudios Pedagógicos, Valdivia, v. 39, n. 1, p. 393-401, 2013. http://dx.doi.org/10.4067/S071807052013000100023

ROITMAN, M. Por la razón o la fuerza: historia de los golpes de Estado, dictaduras y resistencia en América Latina. Madrid: Siglo XXI, 2019.

SAENZ, A. ¡La enseñanza de la Historia sin mujeres! Género, currículum escolar y libros de texto: una relación problemática. Didáctica de las Ciencias Experimentales y Sociales, Valencia, n. 29, p. 43-59, 2015. https://doi.org/10.7203/dces.29.3820

SCOTT,J. La domination et les arts de la résistance. Fragments du discours subalterne. París: Amsterdam, 2009.

SOUTHWORTH, E.; KEMPEN, J.; ZIELINSKI, M. Whose story is it, now? Re-examining women's visibility in 21st century secondary world history textbooks. Teaching Social Studies, Nueva York, v. 19, n. 2, p. 45-57, 2019. Disponible en: https:// digitalcommons.snc.edu/cgi/viewcontent.cgi?article=1012\&context=faculty_staff_ works.Acceso en: 15 dic. 2019.

STUVEN, A. Historia de las mujeres en Chile. Santiago de Chile: Penguin Random House, 2014.

TORRES, J. El currículum oculto. Madrid: Morata, 1998.

TORRES, I. La cultura: Chile (1880-1930). Madrid: Penguin Random House, 2015. VAN DIJK, T. Racismo y discurso en América Latina. Barcelona: Gedisa, 2019.

VAN LEEUWEN, T. The representation of social actors. In: CALDAS, C.; COULTHARD, M. (org.). Texts and practices: readings in critical discourse analysis. Nueva York: Routledge, 1996. p. 32-70.

VAN LEEUWEN, T. Critical discourse analysis and multimodality. In: HART, C.; CAP, P. (org.). Contemporary Critical Discourse Analysis. Londres: Bloomsbury, 2014. p. 281-295.

VERA, J. El sistema de admisión a la universidad: permanencia y cambio. Santiago de Chile: Editorial Universitaria, 2015. 
WODAK, R. Discourse of polictics in action: polictics as usual. Hamsphire Palgrave: MacMillan, 2009.

WOYSHNER, C.; SCHOCKER, J. Cultural parallax and content analysis: images of black women in high school history textbooks. Theory \& Research in Social Education, Londres, v. 43, n. 4, p. 441-468, 2015. https://doi.org/10.1080/00933104.2015.1099487

\section{SOBRE EL AUTOR}

Humberto Andrés Álvarez Sepúlveda es doctor en sociedad y cultura por la Universidad de Barcelona (España). Profesor de la Universidad Católica de la Santísima Concepción (Chile).

E-mail: haalvarez@historia.ucsc.cl

Conflictos of interés: $\mathrm{El}$ autor declara no haber ningún interés comercial o asociativo que represente conflicto de interés no que se refiere al manuscrito.

Financiamiento: El estudio fue financiado por la Vicerrectoría de Investigación y Postgrado (FAA código 02/2019) de la Universidad Católica de la Santísima Concepción, Chile.

Recibido el 22 de febrero de 2020 Aprobado el 17 de septiembre de 2020 